\title{
Perpetrators of rape as reported in Central Hospital, Benin City, Nigeria
}

\author{
Dr. Uchendu Obiorah Jude, Dr. Nwogoh Benedict \\ MB;BS, FWACP (Lab Med.) Department of Pathology, Delta State University Teaching Hospital, Oghara, \\ Delta State, Nigeria \\ MB; BS, FMCPath, FWACP (Lab Med.) Department of Haematology and Blood Transfusion, University of \\ Calabar Teaching Hospital, P.M.B 1278, Calabar, Nigeria
}

\begin{abstract}
Introduction: Rape is a serious and obnoxious crime constituting a violation of the right and freedom of women with adverse effects on its victims. Objective: The study is aimed to analyze the demographic parameters of perpetrators of rape, the instruments of abuse and the environment of the assault.Methodology: this is a descriptive study conducted over a period of 6 months at the central hospital, Benin City. Data was obtained using a structured questionnaire and analyzed using spss version 16. Results: A total of 100 cases were documented during the study period. The mean age of the assailants was 20 years with peak age range of 21-30 years. Neighbours were the highest culprits and majority of abuse were carried out during the day in the homes of assailants. Conclusion: Adolescents and young adults are the commonest perpetrators of rape in Benin City. They are familiar with their victims in majority of cases, using unsuspected instruments to perpetrate their crime.
\end{abstract}

Keywords: Perpetrators, Rape, Benin City.

\section{Introduction}

The crime of rape is as old as mankind yet it has remained the most obnoxious and gravest of all human right violation. ${ }^{1}$ it is the most prevalent and fastest growing crime globally. ${ }^{2}$ it has also been recognized as a gendered crime, constituting a violation of the right and freedom of women and fueling gender inequality. ${ }^{3}$

Its definition varies slightly across countries, culture and religion. According to world health organization, rape is a form of sexual violence, defined as physically forced or otherwise coerced penetration of the vulva or anus. ${ }^{4}$ in the Nigerian context, rape has been legally defined as "unlawful carnal knowledge of a woman or girl, without her consent, or with her consent, if consent was obtained by force or by means of threat or intimidation of any kind, or by fear or harm, or by any means of false and fraudulent representation as to the nature of the act, or in the case of a married woman, by personating her husband".

Studies have shown that rape is associated with several devastating short and long term health consequences including sexual transmitted infections (including HIV/AIDS), genital and non-genital injuries, unwanted pregnancies, attempts at abortion with attendant risk, post-traumatic stress disorders, accidental and homicide death, and suicide resulting from the frustration emanating from rape among others. ${ }^{6}$ Sadly, rape has remained a highly under-reported crime, with a persistently rising incidence, yet with a very poor conviction rate. $^{2,7}$

This study is undertaken to study the characteristics of the accused of rape cases in Benin City, Nigeria with emphasis on their age distribution, relationship of the accused to the victims, environment and time of execution of rape, and methods used to attract its victims.

Setting

\section{Materials and methods}

The study was conducted in Benin City, the capital and the largest city in Edo state (Nigeria) with a population of 2,406,697 people. It is an ancient cosmopolitan city and a home for all tribes in Nigeria. Apart from the police medical centre, located elsewhere in the same city, all criminal cases requiring medical examination (sexual assault inclusive), are usually referred to central hospital, Benin City.

\section{Study Design}

This is a six months prospective study of sexual assault cases seen in the Department of Pathology and Forensic Medicine, central hospital (from July to December 2013). A standard questionnaire was prepared to collect information from patients, the investigating police officer handling the case and the accused where accessible. 


\section{Data analysis}

The findings were analyzed using the statistical package for social sciences (spss) version 16 software and presented in tables, charts and figures.

\section{Ethical approval}

The study was approved by the Edo State Ministry of Health Research and Ethics Committee.

\section{Results}

The mean age of the accused was 20 years. The peak age range of perpetrators was $21-30$ years followed by $11-20$ years as shown in fig. 1 . Twenty eight percent of the accused were involved in gang rape. In 52 cases reported, the accused were neighbours while blood relatives account for $4 \%$ of cases as shown in fig.2. Most $(60 \%)$ cases occured in the assailants home as shown in table 1. Sixty-five percent of cases occured during the day while $35 \%$ were at night.

The use of force was documented in $79(79 \%)$ cases while manipulations (use of bait) was reported in 29 $(29 \%)$ cases. Of cases where force was applied, the use of weapons, restraint and threats were reported in 25,17 and 25 cases respectively. Manipulative tools employed include food, finance and promise of relationship in 7, 4 and 12 cases respectively.

\section{Discussion}

Data on sexual violence can be generated from surveys, police reports, clinical settings and nongovernmental agencies. ${ }^{9}$ though our report is generated from a medicolegal setting, it is significant because in Nigerian context, the sociocultural influence, gender inequality and our judicial system tend to protect the perpetrators, therefore making community-based studies even difficult.

Our study showed that $73 \%$ of the assailants are within the age of 11-30 years, with the peak decade for perpetrators of rape crime occurring in the $3^{\text {rd }}$ decade of life which is comparable to the result of a similar study in india by shinge et al. ${ }^{2}$ similarly, Sagar et al ${ }^{1}$ observed $64 \%$ of accused in the age group of $16-25$ years, while Sarkar et $\mathrm{al}^{8}$ noted a peak in the 21-25 years age group. It can therefore be concluded that teenagers, adolescents and young adult males are most common perpetrators of rape crime.

It was also shown from our study that $72 \%$ of cases involved one perpetrator, while in the rest of the cases; a gang (multiple-perpetrators) was involved. Our finding of multiple perpetrators is intermediate between $44 \%$ reported in South Africa and $25 \%$ reported in us. ${ }^{10}$ the high incidence of gang rape may be attributed to the increasing rate of cultism, gangsterism and armed robbery in the country.

In eighty two percent of rape cases, the accused is known to the victims, and these include relatives, neighbours, friends, friends of other members of the family, teacher, landlords, employers or other authority figures.

Our report also showed that in $60 \%$ of cases studied, the crime is committed in the perpetrator's house. This may be explained by the tendency of the perpetuators to execute the crime where they have the strongest advantage of security, strength and safety relative to the victim. Also because of our sociocultural setting, it is more difficult to believe that the victim did not consent at this setting, impacting negatively on their access to justice. As the victims are usually known to the accused, the unsuspicious victims are easily lured to the perpetrator's house. Uncompleted buildings, bushes, farm, and lonely walk way are also advantageous position for the rapist as the victims are also taken unaware by the assailants, with no one to interfere; these together accounted for $25 \%$ of the cases. Public places like bars and hotels are however uncommon places for execution of rape as seen in our study. The relatively high rate of rape in the victims' house may be attributed to the increasing rate of armed robbery and cultism in our society. The incidence may have been over represented in this study because since it is a hospital based study where more severe cases are likely to be reported.

Our study showed that weapons were used in $19 \%$ of cases. These weapons include guns, stick and knife. This is however lower than the incidence report in South Africa, where a third of reported rape cases involved use of weapons with $55 \%$ of cases involving strangers. ${ }^{11}$ Financial gratification and other supports (including food) were seen in $11 \%$ of cases, and this may be attributed to the level of poverty in our environment. Use of threat was observed in $25 \%$ of cases, and this may have been possible as most of the victims in our environment are children, who are likely to yield to threat.

The study has its limitations. First, it is based on the hospital and police records, which are likely to include mostly the severe cases, and this may not represent the actual incidence in the populace. There is therefore need for a community-based research to ascertain the true prevalence of this assault.

\section{Conclusion}

Our study shows that most reported rape cases occur in the day and in the homes of the perpetrators who are often known to the victims. Use of weapons is uncommon in commissioning of rape in our environment. 
There is however need for further research for more detailed understanding of the profile of the accused of rape crime in nigeria.

\section{Reference}

[1]. Sarkar sc, lalwani s, rautji r, bhardwaj dn and dogra td. Prospective study of victims and offender of sexual offences. The malaysian journal of forensic pathology and science, june 2008; 3(2):10 - 47

[2]. Shrikant ss, manish bs medico-legal examination of accused of alleged rape cases a prospective study.. $\mathrm{J}$ indian acad forensic med. 2013, vol. 35 , no. 4

[3]. Chattoraj n. Sex related offences and their preventive and control measures: an indian perspective; guest paper in resource material series72 at 133rd international training course by unafei; 2006; p 82-99

[4]. Krug eg, dahlsberg 11, mercy ja, zwi ab, lozano r, eds. Chapter 6: sexual violence. In: world health report on violence and health. Geneva: world health organization, 2002: 147-81.

[5]. The criminal code laws of the federation of nigeria 1990. Cap 77

[6]. Rachel jewkes, purna sen, claudia garcia-moreno. Sexual violence. In: etienne g. Krug, linda 1. Dahlberg, james a. Mercy, anthony b. Zwi and rafael lozano.(eds) world report on violence and health, geneva. Who, 2002, p 149-161

[7]. Kelly 1, lovett $\mathrm{j}$ and regan 1, a gap or a chasm? Attrition in reported rape cases, hors 293(home office: london, 2005).

[8]. Sagar ms, sharma rk, dogra td. Study of sexual offences in south delhi. Jfmt.1991; 9(1), $8-11$

[9]. Gessessew a, mengiste mesfin m. Rape and related health problems in adigrat zonal hospital, tigray region, ethiopia. Ethiop.j.health dev. 2004; 18(3):140-144.

[10]. Porter, le, \& alison, lj. Examining group rape: a descriptive analysis of offender and victim behaviour. European journal of criminology 2006; 3 (3):357-381.

[11]. Vetten, 1 , jewkes $r$, et al. Tracking justice: the attrition of rape cases through the criminal justice system in gauteng. Johannesburg, tshwaranang legal advocacy centre. 2008

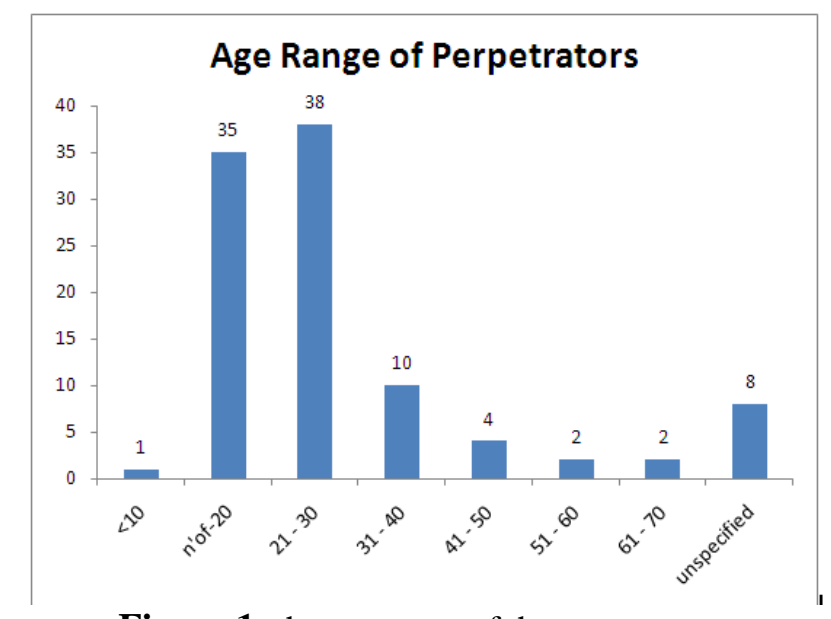

Figure 1: the age range of the perpetrators

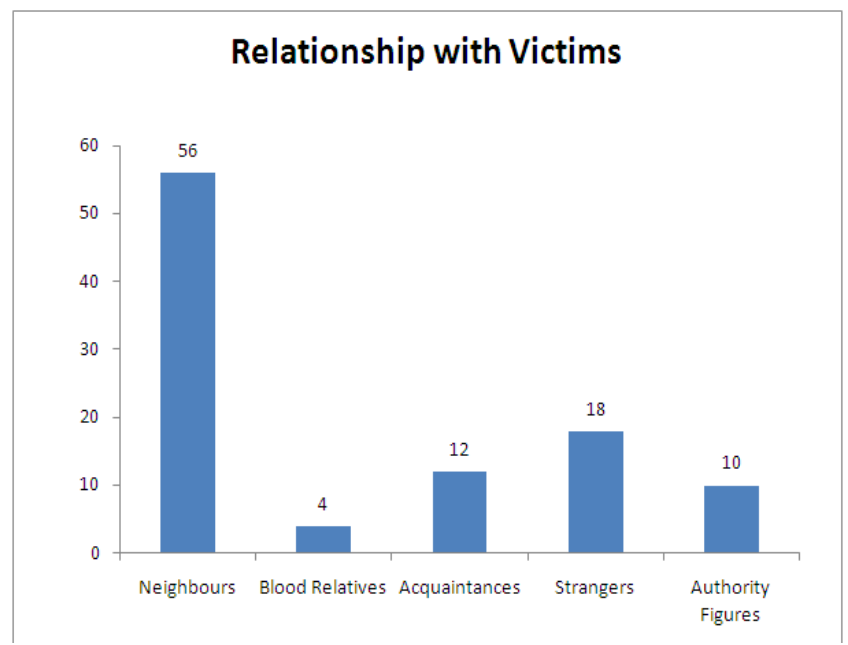

Figure 2: relationship between perpetrators and their victims 
Figure 1: environment of commissioning of rape

\begin{tabular}{|l|l|l|}
\hline Environment & Frequency & Percentage \\
\hline Assailants' home & 60 & 60 \\
\hline Victim's place & 10 & 10 \\
\hline Uncompleted/abandoned buildings & 14 & 14 \\
\hline Bushes and farm & 6 & 6 \\
\hline School compound & 5 & 5 \\
\hline Hotel & 2 & 2 \\
\hline Automobile & 1 & 1 \\
\hline Others & 2 & 2 \\
\hline
\end{tabular}

